\title{
Renewable Energy Generation Technologies on Urban Scale
}

\author{
A. Barragán ${ }^{1}$, P. Arias ${ }^{2}$ and J. Terrados ${ }^{1}$ \\ ${ }^{1}$ Carrera de Ingeniería Eléctrica \\ Universidad Politécnica Salesiana \\ Sede Cuenca - Calle Vieja 12-30 y Elia Liut, Cuenca (Ecuador) \\ Phone.:(+593) 72862213, email ebarragan@ups.edu.ec \\ ${ }^{2}$ Carrera de Ingeniería Eléctrica \\ Universidad Católica de Cuenca \\ Av. de las Américas y Humboldt, Cuenca (Ecuador) \\ Phone.: 593 (07) 2830-751, 593 (07) 2824365, pariasr@ucacue.edu.ec \\ ${ }^{3}$ Departamento de Ingeniería Gráfica, Diseño y Proyectos \\ Universidad de Jaén \\ Campus de las Lagunillas, Edif. Ingeniería y Tecnología (A-3). 23071 Jaén (España) \\ Phone: (+34) 953212825 Fax: (+34) 953 212420, email: jcepeda@ujaen.es
}

\begin{abstract}
Expectations against environmental degradation, including future effects of global warming, require changes in the way how the city is conceived. As an essential, is necessary that public policies and organized planning to consider concepts related to energy supply with the resources that have the cities. Given the enormous pressure of the cities on the environment, the proposed changes are in fact an opportunity to promote sustainability. In a previous study, eleven technologies that use resources available or that come from the cities was determined. It was established that with the widespread use of these technologies, it possible reduce flows from energy carriers that require a city. These energy carriers may be electricity or fuel, and are used for producing heating, power, lighting or data process. Of the technologies described, eight can be used for electricity generation: biomass, biogas from digester, biogas landfill, waste incineration, tidal, wind, small hydro and photovoltaic. The possible use of one or other technology depends not only on the existence of the resource. Is necessary, take in count, technical, economic, social or environmental factors. This research proposes to use multicriteria techniques to analyze holistically the most appropriate option for promoting energy renewable in a particular city.
\end{abstract}

\section{Key words}

Renewable energy, sustainability, energy self-sufficiency, urban planification.

\section{Introduction}

Cities are the result of energy development, on they living more than $50 \%$ of humanity, concentrate buildings, transport, industrial processes or other infrastructure. Urban areas consume more than two thirds of primary energy, which has led to a profound transformation of their inmediate environment, which is reflected in the loss of ecosystems, removal of soil, transformation and contamination of rivers or removal of areas occupied by plants and animals.

Cities have several kinds of energy that can be to incorporated to the local energetic matrix. For example, the renewable energies distributed as solar, micro hydroelectric, wind, or geothermal energy [1]. Although, these proposals may garner environmental merits, it may be difficult for some of the renewable technologies to have a significant share in the urban energy matrix [2]. The long-term challenge is to reshape an energy policy that can modify the demand of the community and promote a change in consumers, market dynamics and political forces [3].
It seeks to take advantage of the local availability of resources to meet the demand for energy of a city [3]. Each community must analyze its own needs, and the resources it has. Hence, it is necessary to study local characteristics to define particular obstacles and opportunities [4], in the face of the inevitable reduction of non-renewable energy resources.

In contrast to the bibliography that exposes information related to large renewable generation plants, this article reviews important topics such as the state of development, costs or environmental implications of technologies that use resources that come from or come from cities. In order to select one or more technologies for a given urban environment, it is proposed to use multi-criteria techniques.

The selected technologies was presented in the study of Barragán and Terrados (2016). Under the urban metabolism approach, 11 renewable energies that have been studied in several cities as options for urban energy supply [5]. The study presents renewable energies that 
use resources available to the city or those that can be re-entered and transformed into energy.

\section{A. Cities}

It is proposed that cities can be designed in a way that considers their energy metabolism. [4]. Under this context, the use and development of renewable energies at the urban level must be considered, which implies the establishing of long-term strategies that aim at a sustainable energy system based on indigenous resources. In the case of cities, of countries with emerging economies, knowledge of their situation can help to define an agenda that includes the energy theme in view of a post oil or technosolar era. [6]. In this sense, Paez (2010) proposes that in addition to the use of renewable resources, the reduction of local demands should be promoted through the adoption of bioclimatic architecture, energy efficiency, passive strategies and the implementation of programs that adopt a circular model of urban metabolism.

The research by Barragán and Terrados identifies 11 subsystems (bioethanol, biomass, biogas from digester, biogas landfill, waste incineration, tidal, wind, geothermal, small hydro, photovoltaic, solar thermal) with varying degrees of maturity that can be applied on cities. In order to define these technologies, the classification of the IDAE of Spain (Instituto para la Diversificación y Ahorro de la Energía) [7] was used, which presents 22 subsystems of renewable technologies. It was established that with the widespread use of these technologies, it is possible to reduce flows from energy carriers required by a city. These energy carriers may be electricity or fuel, and are used for producing heating, power, lighting or data process. Out of the technologies described, eight of these can be used for electricity generation: biomass, biogas from digester, biogas landfill, waste incineration, tidal, wind, small hydro and photovoltaic.

\section{Application of multicriteria methods for selection of renewable energies}

Multiple criteria decision analysis methods (MCDA) help to take decisions between several options or multiple alternatives (a1,a2, ...,ak). The alternatives are evaluated according to a series of attributes $\{\mathrm{g} 1(\cdot), \mathrm{g} 2(\cdot)$, ..., $\operatorname{gk}(\cdot)\}$ that can be qualitative or quantitative. The best alternatives are chosen after making comparisons involving the selected attribut [8], [9].

These techniques have become popular in the decisionmaking in the energetic and environmental fields. There are several multicriteria techniques, being the most popular: AHP - Analytical Hierarchy Process, ELECTRE - ELimination and Choice Translating REality or PROMETHEE - Preference Ranking Organization METHod for Enrichment Evaluation.

For this work, the PROMETHEE (Preference Ranking Organization Method for Enrichment Evaluation) method was used, it was proposed in 1982 by Jean-
Pierre Brans. It is an outranking method that selects or orders alternatives that have criteria that can be conflicting with each other. Brans proposed the versions PROMETHEE I and PROMETHEE II, and next to Bertrand Mareschal, developed III, IV, V and VI versions [10].

To apply the method, it is necessary to establish a set of criteria and sub-criteria (qualitative or quantitative), which will favor the selection process of the renewable alternative to be applied. These sub-criteria were divided into technical, economic and environmental. Table I, presents a summary of the proposed sub criterion used.

Table I. Criteria and sub-criteria

\begin{tabular}{|c|c|c|c|}
\hline Criteria & \multicolumn{2}{|l|}{ Sub - criteria } & \multirow{2}{*}{$\frac{\text { Type }}{*}$} \\
\hline \multirow{5}{*}{ Technical } & Efficiency & T1 & \\
\hline & $\begin{array}{l}\text { Availability of primary } \\
\text { source }\end{array}$ & $\mathrm{T} 2$ & $* *$ \\
\hline & Maturity of technology & T3 & $* *$ \\
\hline & $\begin{array}{l}\text { Urban obstacles and } \\
\text { area availability }\end{array}$ & $\mathrm{T} 4$ & $* *$ \\
\hline & $\begin{array}{l}\text { Architecture } \\
\text { intervention }\end{array}$ & $\mathrm{T} 5$ & $* *$ \\
\hline \multirow{3}{*}{ Economic } & Initial investment & EC1 & $*$ \\
\hline & $\begin{array}{l}\text { Cost of operation and } \\
\text { maintenance }\end{array}$ & EC2 & $*$ \\
\hline & Cost of energy & EC3 & $*$ \\
\hline \multirow{3}{*}{ Environmental } & Global warming & EN1 & * \\
\hline & Acidification & EN2 & * \\
\hline & Eutrophication & EN3 & * \\
\hline \multirow[b]{3}{*}{ Sociopolitical } & Job & S1 & $*$ \\
\hline & Social Acceptability & $\mathrm{S} 2$ & $* *$ \\
\hline & $\begin{array}{l}\text { Compatibility with } \\
\text { international, regional or } \\
\text { local policies }\end{array}$ & S3 & $* *$ \\
\hline
\end{tabular}

The criteria must be maximized (max) or minimized (min), depending on the objective of the problem:

1) Efficiency: It is the coefficient between the output energy and the energy contained in the primary source. For this research, it is considered of qualitative type, and is maximized because higher efficiency is greater the energy available.

2) Availability of primary source: This criterion indicates whether primary energy is available for the use of a given technology. The criterion used for this work is the qualitative type, where, 3 indicates high availability, 2 medium availability, 1 low availability, 0 no availability.

3) Maturity of technology: This criteria indicates the degree of maturity of the technology, the commercial level (C) imply that it is ready to be used. While the level of research and development (R \& D), they are being tested in the laboratory. A qualitative scale is considered in which, 3 indicates commercial maturity, 2 development, 1 research and development. For this criterion it is considered that the technology is viable to implement while the scale is higher. 
4) Urban obstacles and area availability: One of the conditions for the implementation of technologies in the city limits is the space required for their installation. This criterion is consider to be qualitative, and is qualified as 1 , if the installation need additional area, or 0 if not.

5) Architecture intervention: The intrusion of infrastructures of energy generation within the urban space can modify the appearance of the city. This criterion will depend on particular aspects of each city. This criterion is considered qualitative, establishing the following scale: 3 high impact, 2 medium impact, 1 low impact, 0 without impact.

6) Initial investment: This is one of the most used sub criteria to compare alternatives of electric power production, which includes renewable technologies. It includes the cost of technology, installation, construction of roads, connection to the network, and engineering services among others.

7) Cost of operation and maintenance: This criterion considers the costs required for the operation of the system (personnel, products or services), and the costs that allow the operation of the technology during its useful life.

8) Cost of energy: This criterion considers the monetary value of producing a unit of electrical energy. The preference is given to technologies that produce energy at the lowest cost.

9) Global warming: Greenhouse gas emissions cause global warming. This criterion is of the quantitative type, and indicates the amount of emissions of $\mathrm{CO}_{2}$ in the technology life cycle.

10) Acidification: Sulfur dioxide is a gas that oxidizes and causes acid rain, which causes diseases to the ecosystems and the health of the people. This criterion is of the quantitative type, and indicates the amount of emissions of $\mathrm{SO}_{2}$ in the technology life cycle.

11) Eutrophication: The burning of fossil fuels produces nitrogen oxides. In the case of NOx emissions, the main environmental problem is eutrophication that occurs due to excess nutrients deposited in water or soil. This criterion is of the quantitative type, and indicates the amount of emissions of NOx in the technology life cycle.

12) Job: The possibility of developing, manufacturing, installing, constructing, maintaining and operating new infrastructures will require personnel and work force. The increase in employment improves the quality of life of people and enables the establishment of new businesses.

13) Social Acceptability: This sub criterion considers whether the urban population agrees with the installation of renewable technologies. It was proposed a scale where the high acceptability is valued as 3 , the mean as 2 , the low 1 , and without acceptability with 0 .

14) Compatibility with international, regional or local policies: The growing participation of renewable energies in national contexts has been due to the implementation of policies that motivate the installation of this type of technologies mainly on a large scale. In this case, it is considered if there are policies at the local level, a scale is proposed that indicates 0 if there are no local policies for the incentive of the technologies and 1 if they exist.

\section{Case study. Cuenca, Ecuador}

The proposal was applied in the city of Cuenca, Ecuador. Cuenca is the third most important city in Ecuador, it is found in the Inter-Andean Region (South America) in the southern part of Ecuador. The city is crossed in several sectors by four rivers. It is located at 2.550 meters above sea level. It has an urban population of around 300000 inhabitants. Ecuador has a lot of hydroelectric resources, and is an oil producer. In Appendix 1, the evaluation of the sub criteria is presented. The quantitative sub criteria, have been obtained mainly from bibliographic sources, while the qualitative are perceptions of local experts.

Weights: Each criterion and sub criteria has a different impact on the alternatives, therefore they are assigned a weight to indicate their relative importance [9]. As a first approximation to the investigation, it is considered that the weights are equal (1/14).

\section{PROMETHEE Results}

Using the PROMETHEE method, partial ordering (Phi + positive flows and Phi - negative flows) and a complete ordering (net Phi flows) are obtained for the comparison of alternatives. In Figure 1, a flow diagram corresponding to the results obtained using the PROMETHEE GAIA software are presented [10].

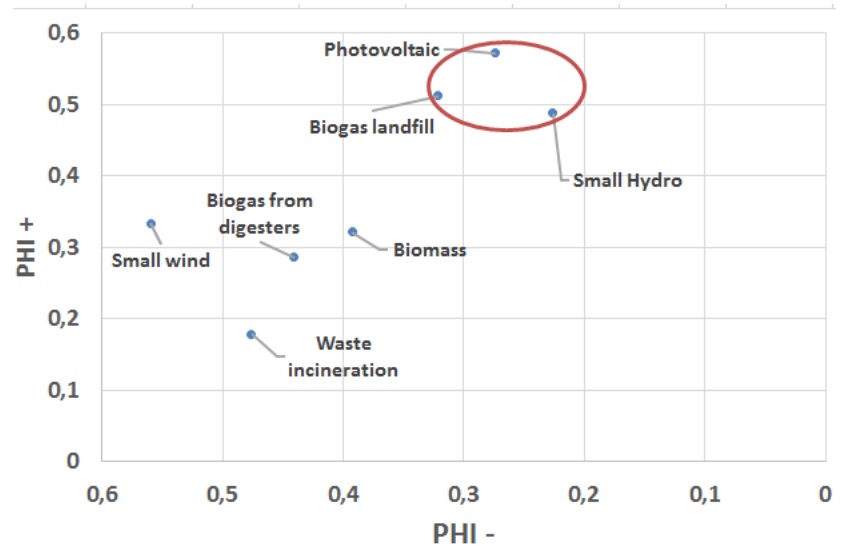

Fig 1. Flux diagram

The negative and positive preference flows (PROMETHEE I) as well as the net flows (PROMETHEE II) are shown in Figure 2. When evaluating net flows, solar photovoltaic, hydroelectric and biogas of landfills, have better preference. The evaluation of negative and positive flows in addition to net flows also indicate that these alternatives are preferred. 


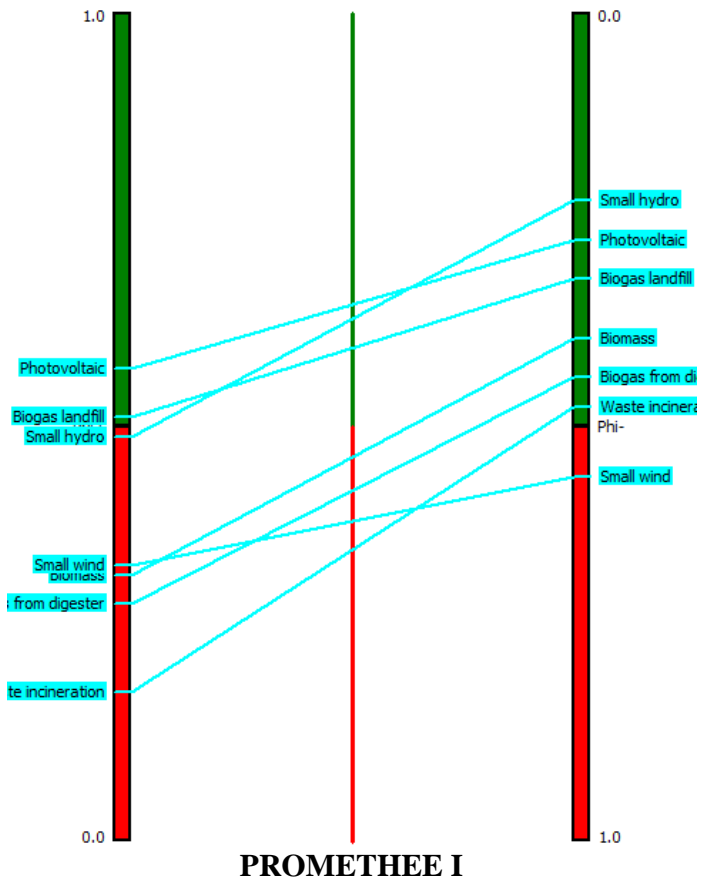

Fig. 2. Results PROMETHEE I (Left) and PROMETHEE II (Right)

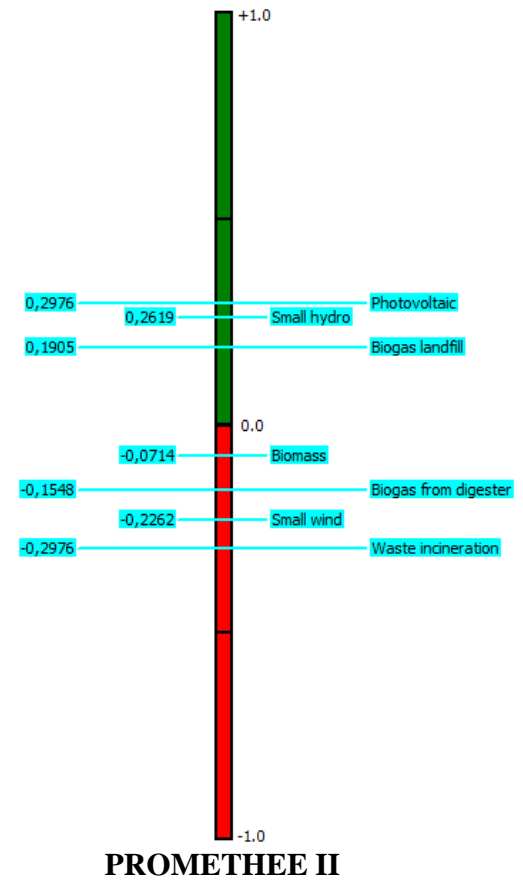

ranking of the alternatives. Thus, the decision maker can select the most appropriate renewable technology based on the established criteria.

Under this approach the technologies that can be applied in the city of Cuenca (Ecuador) was determined. Depending on the degree of preference they are: solar photovoltaic, hydropower, landfill biogas, biomass, biogas, wind, incineration. It was found, that the preferred alternatives depend mainly on the technical, social and economic criteria.

With the above it is concluded, that a change an energy model based on imports of resources from outside of the city, and that consider renewable energy, will require a holistic analysis, to define what the most appropriate options for a given city.

\section{References}

[1] T. Dixon, M. Eames, J. Britnell, G. B. Watson, and M. Hunt, "Urban retrofitting: Identifying disruptive and sustaining technologies using performative and foresight techniques," Technol. Forecast. Soc. Change, vol. 89, pp. 131-144, 2014.

[2] H. Ren, W. Zhou, K. Nakagami, W. Gao, and Q. $\mathrm{Wu}$, "Feasibility assessment of introducing distributed energy resources in urban areas of China,” Appl. Therm. Eng., vol. 30, no. 16, pp. 2584-2593, 2010.

[3] P. S. Grewal and P. S. Grewal, "Can cities become self-reliant in energy? A technological scenario analysis for Cleveland, Ohio,” Cities, vol. 31, pp. 404-411, 2013.

[4] W. R. W. A. Leduc and F. M. G. Van Kann, "Spatial planning based on urban energy harvesting 
toward productive urban regions,” J. Clean. Prod., vol. 39, pp. 180-190, 2013.

[5] A. BARRAGÁN and J. TERRADOS, "Sustainable Cities: An Analysis of The Contribution Made By Renewable Energy Under The Umbrella Of Urban Metabolism,” Int. J. Sustain. Dev. Plan., vol. 12, no. 3, pp. 416-424, Apr. 2017.

[6] A. Páez, "Energy-urban transition: The Mexican case,” Energy Policy, vol. 38, no. 11, pp. 7226-7234, 2010.

[7] IDAE, "Plan de Energias Renovables 2011 2020," Http://Www.Idae.Es/Index.Php/Id.670/Mod.Pags/Mem.

Detalle, pp. 1-824, 2011.

[8] S. D. Pohekar and M. Ramachandran, “Application of multi-criteria decision making to sustainable energy planning - A review,” Renew. Sustain. Energy Rev., vol. 8, no. 4, pp. 365-381, 2004.

[9] J. J. Wang, Y. Y. Jing, C. F. Zhang, and J. H. Zhao, "Review on multi-criteria decision analysis aid in sustainable energy decision-making," Renew. Sustain. Energy Rev., vol. 13, no. 9, pp. 2263-2278, 2009.

[10] B. Mareschal, "Visual PROMETHEE manual," 2013.

Appendix 1 shows the results of the valuation of the different subcriteria, for the Cuenca city, Ecuador.

\begin{tabular}{|c|c|c|c|c|c|c|c|c|c|c|c|c|c|c|}
\hline \multirow{4}{*}{ ai $g j(\cdot)$} & \multicolumn{5}{|c|}{ Technical } & \multicolumn{3}{|c|}{ Economic } & \multicolumn{3}{|c|}{ Environmental } & \multicolumn{3}{|c|}{ Sociopolitical } \\
\hline & $\mathrm{T} 1$ & $\mathrm{~T} 2$ & T3 & $\mathrm{T} 4$ & $\mathrm{~T} 5$ & EC6 & EC7 & EC8 & EN9 & EN10 & EN11 & $\mathrm{S} 1$ & $\mathrm{~S} 2$ & S3 \\
\hline & $\%$ & & & & & $\begin{array}{l}\text { USD/ } \\
\mathrm{kW}\end{array}$ & $\begin{array}{l}\text { USD/ } \\
\mathrm{kW}\end{array}$ & $\begin{array}{l}\text { USD/ } \\
\text { kWh }\end{array}$ & $\begin{array}{l}\text { gCO2e/ } \\
\text { TJ }\end{array}$ & $\begin{array}{l}\text { gSO2e } \\
\text { /TJ }\end{array}$ & $\begin{array}{l}\text { gNOxe/ } \\
\text { TJ }\end{array}$ & $\begin{array}{l}\text { Job } \\
\text { year/ } \\
\text { Gwh }\end{array}$ & & \\
\hline & $\mathrm{M}^{*}$ & $\mathrm{M}$ & $\mathrm{M}$ & $\mathrm{m}$ & $\mathrm{m}$ & $\mathrm{m}$ & $\mathrm{m}$ & $\mathrm{m}$ & $\mathrm{m}$ & $\mathrm{m}$ & $\mathrm{m}$ & $\mathrm{M}$ & $\mathrm{M}$ & $\mathrm{M}$ \\
\hline Biomass & 23 & 2 & 3 & 1 & 2 & 2230 & 74 & 43,08 & 9979 & 42 & 403 & 0,15 & 1 & 0 \\
\hline Biogas from digester & 26 & 2 & 3 & 1 & 2 & 5056 & 809 & 175,35 & 3056 & 201 & 160 & 0,91 & 1 & 0 \\
\hline Biogas landfill & 28 & 3 & 3 & 1 & 1 & 1598 & 118 & 37,87 & 209490 & 854 & 756 & 0,67 & 2 & 1 \\
\hline Waste incineration & 23 & 2 & 3 & 1 & 2 & 6440 & 258 & 126,75 & 100000 & 444 & $\mathrm{n} / \mathrm{a}$ & 2,64 & 1 & 0 \\
\hline Tidal & $\mathrm{n} / \mathrm{a} * *$ & $\mathrm{n} / \mathrm{a}$ & $\mathrm{n} / \mathrm{a}$ & $\mathrm{n} / \mathrm{a}$ & $\mathrm{n} / \mathrm{a}$ & $\mathrm{n} / \mathrm{a}$ & $\mathrm{n} / \mathrm{a}$ & $\mathrm{n} / \mathrm{a}$ & $\mathrm{n} / \mathrm{a}$ & $\mathrm{n} / \mathrm{a}$ & $\mathrm{n} / \mathrm{a}$ & $\mathrm{n} / \mathrm{a}$ & $\mathrm{n} / \mathrm{a}$ & $\mathrm{n} / \mathrm{a}$ \\
\hline Small hidro. & 85 & 2 & 3 & 1 & 2 & 3493 & 70 & 68,42 & 3002 & 6 & 12 & 1,39 & 2 & 0 \\
\hline Small wind & 20 & 1 & 2 & 0 & 3 & 4701 & 150 & 458,32 & 4332 & 12 & 12 & 0,41 & 2 & 0 \\
\hline Photovoltaic & 18 & 3 & 3 & 0 & 2 & 2659 & 32 & 223,03 & 23143 & 80 & 64 & 1,29 & 3 & 1 \\
\hline
\end{tabular}

*The criteria must be maximized (M) or minimized (m)

** Not applicable because it is not a coastal city 